\title{
MODELOS SUCESSÓRIOS EM PROPRIEDADES RURAIS: UM ESTUDO NO MUNICÍPIO DE CRUZ ALTA/RS
}

\author{
Sandro da Luz Moreira* \\ Rosani Marisa Spanevello**
}

\begin{abstract}
Resumo
A sucessão geracional em propriedades rurais, em especial do Sul do Brasil, é caracterizada por um modelo sucessório tardio em que os pais esperam os limites da idade para passar a gestão dos negócios e o patrimônio aos filhos. No entanto, as possibilidades da migração juvenil rural impõem novas perspectivas quanto à sucessão, podendo gerar modelos distintos. O objetivo deste artigo é discutir as formas como vem ocorrendo a sucessão geracional em propriedades rurais, buscando identificar a possibilidade de elaboração de novos arranjos referentes ao processo sucessório. $\mathrm{O}$ espaço empírico da coleta de dados foi o município de Cruz Alta/RS, através da realização de 31 entrevistas com produtores rurais com sucessão geracional nas propriedades. Para a análise e elaboração dos modelos, foram consideradas três variáveis: local de moradia; administração do negócio e gerenciamento da renda. Os resultados apontam uma diversidade de modelos sucessórios. No total, foram elaborados seis modelos que demonstram que a sucessão geracional vem ocorrendo de distintas formas incluindo a possibilidade de os sucessores residirem no meio urbano, com maior ou menor autonomia no gerenciamento dos negócios e da renda. Estes resultados sugerem que o processo da sucessão geracional em propriedades rurais vem acontecendo em propriedades em que os pais motivam a permanência dos filhos garantindo a estes autonomia no gerenciamento de atividades produtivas, moradia e renda como forma de fomentar a sua permanência.
\end{abstract}

Palavras-chave: Sucessão geracional. Modelos. Propriedades rurais.

\footnotetext{
* Mestre em Agronegócios pela Universidade Federal de Santa Maria (UFSM).E-mail: sandromoreira_rs@hotmail.com

** Doutora em Desenvolvimento Rural pela Universidade Federal do Rio Grande do Sul (UFRGS). Docente Professora Adjunta do Curso de Zootecnia e do Programa de Pós-Graduação em Agronegócios da Universidade Federal de Santa Maria (UFSM), Campus Palmeira das Missões/RS. E-mail: rspanevello@yahoo.com.br
} 
1 Neste trabalho foram utilizadas propriedades rurais de todos os tamanhos e características produtivas do município de Cruz Alta. Todas em processo de sucessão geracional definida ou encaminhada, com o sucessor trabalhando $\mathrm{e}$ morando (ou não) na propriedade. A classificação das propriedades rurais em relação ao tamanho da área é definida pela Lei no 8.629, de 25 de fevereiro de 1993 e leva em conta o módulo fiscal (e não apenas a metragem) que varia de acordo com cada município. Os imóveis rurais são classificados em: Minifúndio - imóvel rural com área inferior a 1 (um) módulo fiscal; Pequena Propriedade imóvel de área compreendida entre 1 (um) e 4 (quatro) módulos fiscais; Média Propriedade - o imóvel rural de área superior a 4 (quatro) e até 15 (quinze) módulos fiscais; Grande Propriedade - imóvel rural de área superior 15 (quinze) módulos fiscais (INCRA, 2017). No município, o módulo rural é 20 hectares.

\section{Introdução}

Tradicionalmente, as propriedades rurais $^{1}$ se reproduzem pela passagem da gestão dos negócios e do patrimônio dos pais para os filhos sob a perspectiva da reprodução de longo prazo, como considera Almeida (1986). Uma das particularidades do meio rural, de acordo com Champagne (1986), é que a produção agropecuária tende a ser executada por pessoas ligadas a ela, sendo considerada uma atividade endógena. Ainda segundo este autor, a perspectiva de ser agricultor parte de quem é filho de agricultor, pois dificilmente uma pessoa do meio urbano retorna ao rural para exercer esta atividade. Conforme mencionam Silvestro et al. (2001), Gasson e Errigton (1993), Spanevello (2008), a manutenção dos filhos na propriedade e na ocupação paterna faz parte das estratégias de reprodução social das famílias, sendo este processo conhecido como sucessão geracional.

Uma das principais características da sucessão geracional é a forma como este processo é feito dentro das famílias. Estudos pioneiros sobre a reprodução social do meio rural realizados na região sul do Brasil, tais como o de Woortmann (1995), Abramovay et al. (1998), Silvestro et al. (2001), dão conta de mostrar que a sucessão geracional está baseada em um determinado modelo com as seguintes características: o sucessor é o filho mais novo ou o mais velho, geralmente do sexo masculino, que passa a herdar não só a ocupação mas o patrimônio e a responsabilidade de cuidar dos pais na velhice (SPANEVELLO et al. 2017), segundo a lógica de que todo filho de agricultor seria um agricultor. Outro aspecto marcante deste modelo de sucessão geracional está relacionado com a gestão do negócio que fica a cargo do pai até que suas condições de saúde e trabalho cheguem ao limite da idade, ou seja, a gestão dos negócios e a posse do patrimônio tende a ocorrer tardiamente, dentro de um modelo denominado de sucessão tardia (ABRAMOVAY et al., 1998; SILVESTRO et al., 2001; SPANEVELLO, 2008). A sucessão geracional era vista como um "acontecimento natural", pois, no passado, os filhos ficavam por obrigação moral, pelo amor a terra e para manter a coletividade da família e a reprodução do patrimônio entre as gerações.

No entanto, as mudanças estruturais do meio rural das últimas décadas (BOURDIEU, 2000, SILVESTRO et al., 2001) geraram uma série de impactos sobre a forma de produzir e sobre o contingente populacional com especial atenção à redução do número de pessoas no campo, especialmente o estrato juvenil. No caso do Rio Grande do Sul, segundo o Instituto Brasileiro de Geografia e Estatística (IBGE, 2018), a queda da população juvenil é mais acentuada a partir da década de 1990 com uma redução de 44,4\% da população rural jovem, 15,6\% em 2000 e 34,6\% na década de 2010 em relação ao censo de 1970. Diversos estudos realizados 
no Rio Grande do Sul se voltaram a compreender o processo de saída dos filhos de agricultores do campo e os fatores motivacionais para a migração urbana e a consequente ausência de sucessão das propriedades e até mesmo a problemática das famílias e das terras quando filhos desistem da ocupação agrícola. Tais dificuldades podem ser a permanência dos pais com idade avançada no campo (envelhecimento), a redução da mão de obra juvenil nas atividades agropecuárias, a possibilidade de venda ou arrendamento das propriedades, a masculinização, entre outras.

Apesar da importância dos estudos destacados acima, realizados em distintas realidades geográficas, sociais, produtivas e econômicas, que mostram as dificuldades em torno da questão sucessória das propriedades rurais, é possível afirmar que, em determinadas condições, as propriedades rurais vêm conseguindo garantir a sucessão geracional. Spanevello (2008) e Spanevello et al. (2011) retrata que as chances do processo sucessório se concretizar estão diretamente relacionadas com o potencial produtivo da propriedade, da possibilidade de modernização e da capitalização da família, além do "discurso" positivo dos pais sobre a ocupação e a agricultura e da inserção dos filhos desde cedo na gestão e do trabalho da propriedade.

Este artigo tem como pano de fundo discutir a sucessão geracional sob a perspectiva das propriedades que possui sucessão geracional. Os estudos sugerem que a permanência dos filhos na condição de sucessores está atrelada a uma série de condicionantes sociais, econômicos e estruturais internos e externos à família e à propriedade. $\mathrm{O}$ próprio processo da sucessão geracional, segundo Woortmann (1995) e Spanevello et al. (2014), não é um processo natural como nas gerações passadas, o que pressupõe pensarmos que a forma como vem ocorrendo a sucessão geracional não está atrelada ao modelo tardio, podendo ocorrer derivações ou modificações destes ou mesmo novos modelos. Estas derivações, segundo o trabalho de Gasson e Errington (1993), podem representar a possibilidade de os sucessores serem os gestores dos negócios antes da concretização do processo sucessório ou até mesmo compartilhar a gestão com os pais; residir na propriedade ou mesmo fora dela, ter autonomia de decisão nos negócios ou pelo menos no negócio que está sob seu comando; possuir poder de decisão sobre a renda gerada ou ter renda própria, entre outros. Essas são características que diferem do modelo de sucessão tardia como é citado pela literatura referente ao tema, em especial no sul do Brasil.

O objetivo deste artigo é discutir as formas como vem ocorrendo a sucessão geracional em propriedades rurais, buscando identificar a possibilidade de elaboração de novos arranjos referentes ao processo sucessório a partir da realidade encontrada. Os modelos são construídos a partir da forma como os pais inferem na autonomia do trabalho e na gestão dos sucessores. 
O artigo está estruturado em cinco tópicos, sendo o primeiro a introdução, o segundo os procedimentos metodológicos, o terceiro compreende a revisão bibliográfica, o quarto os resultados e as discussões e, por fim, as principais conclusões.

\section{Revisão bibliográfica}

A revisão bibliográfica compreende a apresentação dos principais conceitos que norteiam o objetivo deste artigo. $\mathrm{O}$ primeiro item trata da discussão sobre a caracterização do processo sucessório nas propriedades rurais e o segundo discute as possibilidades de novos arranjos em torno da sucessão geracional.

\section{Caracterização do processo sucessório nas propriedades rurais}

Ao longo das gerações, especialmente no Sul do Brasil, a sucessão geracional é reconhecida pelo fato de ser tardia. Esse tipo de sucessão, segundo Abramovay (1998) e Spanevello (2008), tem como principal característica o encaminhamento e a divisão do patrimônio quando a geração atual (dos pais) julgar conveniente fazer este processo, sendo geralmente ao final da vida. Para Spanevello (2008, p. 210), “[...] a sucessão tardia é um processo de responsabilidade do pai e resolvida de forma tardia ou quando os pais atingem a (in)capacidade física para o trabalho". Desta maneira, "[...] o pai, na condição de chefe do estabelecimento, determina o encaminhamento do estabelecimento através da transmissão do patrimônio aos filhos" (SPANEVELLO, 2008, p. 210).

Estudos como o realizado por Abramovay et al. (1998) aponta que a sucessão ou a renovação da mão de obra na agricultura é tradicionalmente marcada pelo poder paterno e está articulada em torno da figura do homem, que determina o momento e a forma da passagem das responsabilidades sobre a gestão do estabelecimento para a próxima geração. A transição leva em conta muito mais a capacidade e disposição de trabalho do pai do que as necessidades do sucessor ou as exigências econômicas ligadas ao próprio desenvolvimento da atividade (ABROMOVAY et al., 1998).

Segundo Paulilo (2004, p. 235): “O/os sucessor/es só poderá/ão assumir a responsabilidade pela exploração agrícola quando o pai ou se retira da atividade ou morre". A aposentadoria não significa parar de trabalhar, mas receber todo mês um pequeno montante de dinheiro bastante apreciado. Isso significa dizer que o pai vai se manter no controle do negócio enquanto puder ou enquanto as limitações de saúde e idade não se tornarem um agravante. Conforme Gasson e Errignton (1993), o controle do pai sobre o negócio, em especial a demora em transferir este controle, pode resultar em 
sucessores menos preparados administrativamente para tocarem o negócio, pois sempre estiveram à "sombra do pai". Este retardo tem suas explicações: 1) Trata-se de uma questão cultural, pois os pais (atuais gestores) vêm de modelos sucessórios semelhantes nas gerações passadas; 2) Segundo Paulilo (2004, p. 235), com o aumento da longevidade da população, especialmente dos mais idosos, "os que trabalham junto à família ficam na posição de dependente por longo tempo", o que significa afirmar que os pais ainda são a voz de comando na administração das propriedades, ainda que os filhos estejam preparados para assumir o negócio. Como resultado, segundo Abramovay et al. (1998), embora pais e filhos tenham contato como trabalhadores dentro das propriedades durante longos anos, muitas vezes os pais conduzem as propriedades sem a efetiva participação dos filhos, vendo-os mais na função de mão de obra do que como gestores.

\section{Possibilidades de novos arranjos em torno da sucessão geracional}

Atualmente a sucessão geracional, segundo Woortmann (1995) e Spanevello et al. (2014), não é um processo natural como nas gerações passadas. Sob a perspectiva do trabalho de Ellis (2000), é possível ver que as famílias dispõem de distintos capitais: natural, físico, humano, financeiro e social. Segundo o autor, os produtores mobilizam estes capitais como forma de diversificar os meios de vida e objetivando garantir a sua reprodução social e econômica, como é o caso da sucessão geracional. Ou seja, as condições ou os capitais que levam as famílias a diversificar os meios de vida também implicam a construção de diferentes formas e arranjos sucessórios.

Conforme Woortmann (1995), para garantir um sucessor hoje é preciso cativá-lo. Nesse sentido, segundo Spanevello et al. (2014), os produtores montam diferentes estratégias como forma de assegurar ao menos a presença e o interesse de um filho para seguir na atividade. $\mathrm{E}$ as formas de cativar um sucessor podem ser diversas, incluindo bens materiais e simbólicos. Entre os bens materiais, os pais compram ou repassam área de terra para os filhos, renda própria do filho sucessor pelo trabalho executado na propriedade, constroem moradias separadas para os jovens casais (ainda de dentro da mesma propriedade), compram motocicletas ou carros como forma de garantir a mobilidade e a autonomia produtiva e financeira, bem como investem em maquinário na propriedade (visando à diminuição do trabalho). No tocante aos bens simbólicos, os autores argumentam que o próprio discurso positivo dos pais referente à atividade agrícola é um fator motivador.

Essas questões mencionadas sugerem que os pais buscam construir a sucessão das suas propriedades não esperando apenas a decisão de ficar ou sair dos filhos, podendo gerar outros modelos sucessórios distintos da 
sucessão tardia (aquele em que os pais passam os negócios apenas quando a capacidade física não permite mais).

O trabalho de Gasson e Errignton (1993) sugere distintos arranjos no que se refere à sucessão geracional de propriedades rurais a partir de variáveis como autonomia do negócio, local de moradia e gerenciamento de renda. Os arranjos são basicamente quatro. O primeiro arranjo é marcado pela autonomia do filho em residir em uma propriedade rural separadamente do pai e estabelece uma forma própria de gestão e exerce o processo de tomada de decisão de forma independente. Também é independente financeiramente, mas assume o estabelecimento paterno em caso de aposentadoria do pai; assim, o filho pode compartilhar máquinas com a propriedade rural do pai de modo cooperativo em horários alternativos. Pode até começar a construir uma base de capital separada para pagar os pais ou irmãos quando ele tomar posse da propriedade rural da família. $\mathrm{O}$ segundo sugere que o filho possui um "negócio separado" na propriedade e tem boa autonomia na atividade que realiza, podendo ser, por exemplo, uma criação de suínos. O filho aprende a desenvolver ou aprimorar as habilidades que adquiriu com o pai e possui relativa independência financeira, o que the permite construir algum capital próprio. Já no terceiro, o filho reside com o pai e eles trabalham em forma de parceria. O filho vai gradualmente aumentando sua responsabilidade na realização de algumas atividades, com possibilidade de tomada de decisão em determinadas tarefas em comum acordo com o pai. Por fim, no quarto modelo, o filho mora com o pai, mas participa muito pouco do processo de tomada de decisões das atividades do estabelecimento, apesar de conviver e trabalhar com seu pai e sua família por muitos anos na mesma propriedade. O filho é tido como uma força de trabalho importante na propriedade rural e assume o papel de sucessor em caso da morte ou aposentadoria do pai, podendo apresentar dificuldades na gestão dos negócios devido à dependência do pai por longo tempo (GASSON; ERRINGTON; 1993; ERRINGTON, 2002).

Em síntese, os quatro modelos retratados reforçam existir um primeiro modelo que retrata uma autonomia administrativa e financeira maior, inclusive como local de moradia fora da propriedade, enquanto o segundo e terceiro retratam uma autonomia relativa do sucessor, tendo este autonomia em parte da gestão do negócio e em parte da renda, enquanto o quarto aponta para a ausência de autonomia colocando o sucessor na posição de dependente do pai.

É importante ressaltar que esses modelos propostos retratam a realidade do Reino Unido e foram elaborados há quase duas décadas por Gasson e Errignton. No entanto, isso não significa que a proposta não tenha validade para outros contextos rurais ou que sejam modelos ultrapassados. Conforme o que as autoras ressaltam, as formas como cada família e 
propriedade fazem a sucessão envolve uma série de questões produtivas, econômicas, sociais e culturais em momentos distintos da sua trajetória que dificultam inclusive a elaboração de "modelos puros". Na realidade, os padrões sucessórios combinam um ou vários elementos de um tipo ou de outro. O que move essas combinações são não somente as particularidades individuais das famílias e dos filhos, mas também as variações geográficas e temporais. Ademais, embora prevaleçam as normas sociais e legais em torno da transferência dos estabelecimentos, é provável que o ambiente econômico (diversificação produtiva, tamanho da área) também favoreça ou defina as oportunidades ou restrições à sucessão dos estabelecimentos (SPANEVELLO, 2008).

\section{Procedimentos metodológicos}

O detalhamento metodológico do artigo trata de apresentar a descrição do município onde foi realizada a pesquisa, a forma de realização da coleta e a análise dos dados.

\section{Descrição do município}

O espaço geográfico da coleta de dados é o município de Cruz Alta, situado na região noroeste do estado do Rio Grande do Sul. Considerando o contingente populacional do município, são 62.821 habitantes no total, entre os quais 3,5\% vivem no campo. O município de Cruz Alta, segundo os dados dos Censos Demográficos, apresentou uma significativa diminuição da população rural, em que cerca de $83 \%$ da população deixou o campo entre os anos de 1970 e 2010 . Aproximadamente $81 \%$ dos jovens migraram ou saíram do meio rural entre 1970 e 2010 . Ou seja, saem jovens, e esse fato reflete a falta de sucessão, de mão de obra e o envelhecimento do meio rural do município.

Segundo o Censo Agropecuário de 2006, o número total de propriedades do município era de 617, já os dados preliminares do Censo Agropecuário de 2017 registra uma redução para 580 propriedades; destas, $88 \%$ possuem a gestão conduzida por homens e apenas $12 \%$ por mulheres. Outro dado importante quando se trata da questão sucessória é a idade dos produtores: apenas 2,7\% das propriedades têm jovens, menores de 30 anos, à frente da gestão, pressupondo as dificuldades do processo sucessório no município, conforme dados preliminares do (IBGE, 2017). A maior parte das terras ocupadas no município apresenta como principais produtos agrícolas as culturas de soja, milho e trigo. Na pecuária, destaca-se a produção de leite. A maior parte das propriedades é caracterizada como média e grande. Em áreas de agricultura familiar, inclusive em assentamentos de reforma agrária, é percebido o mesmo tipo de cultivo que é feito nas médias 
e grandes propriedades (CAMPOS; MEDEIROS, 2012). Percebe-se que aproximadamente $43 \%$ das propriedades rurais do município não são familiares, com média de 368 ha e $57 \%$ são familiares com média de 15,5 hectares. Ou seja, quanto à distribuição, as propriedades são semelhantes, não há uma disparidade muito representativa; já com relação à divisão de área, $5 \%$ da área total do município é utilizada pela agricultura familiar e $95 \%$ pela não familiar.

\section{Coleta e análise de dados}

A coleta de dados ocorreu por meio de entrevistas realizadas nas propriedades rurais em que se dá o processo de sucessão geracional. $\mathrm{O}$ entrevistado é um dos pais (sendo ou não o principal gestor da propriedade rural), obedecendo aos critérios de seleção propostos no trabalho de Spanevello (2008): ter pelo menos um(a) filho(a), independentemente do sexo; agricultores com idade de 50 anos ou mais. Esse recorte etário se justifica pelo fato de a pesquisa estar centrada em casos de situação definida ou encaminhada de sucessão. A literatura referente ao tema aponta que a sucessão é um processo tardio, ou seja, os pais encaminham ou realizam a transmissão do patrimônio quando atingem idade mais avançada. Isto é necessário para evitar o risco de entrevistarmos agricultores jovens ou recém-estabelecidos ou mesmo com filhos pequenos; agricultores com sucessão; haver pelo menos um filho residindo na propriedade rural (ou em outra propriedade próxima) já definido ou encaminhado como sendo o sucessor.

No total, foram realizadas 31 entrevistas, abarcando distintas propriedades em termos de tamanho, sistemas produtivos e locais de residência dos gestores. Este número de 31 entrevistados ocorreu pelo fato da amostra ser por conveniência, considerando que não é o tamanho da amostra que define se o estudo é confiável e de qualidade, e sim as informações e materiais coletados nos processos que responderão aos problemas do estudo.

Os dados foram analisados com a técnica de análise de conteúdo (BARDIN, 1977; CAMPOS et al., 2004). A partir da análise do conteúdo das entrevistas, os resultados da pesquisa foram sistematizados conforme as características do processo sucessório de cada propriedade. A caracterização foi realizada com base em três variáveis centrais: local de moradia do sucessor, gerenciamento dos negócios e gerenciamento da renda. A análise destas características permite a construção dos cenários distintos de sucessão denominados de modelos sucessórios. Este arranjo dos modelos tem como suporte teórico metodológico o trabalho de Gasson e Errington (1993). No total, os resultados analisados geraram seis modelos. 
Para a elaboração dos modelos foram selecionadas três variáveis: 1) Local de moradia; 2) Administração do negócio; 3) Gerenciamento da renda, conforme exposto na Figura 1 abaixo.

Figura 1 - Esquema das variáveis dos modelos sucessórios

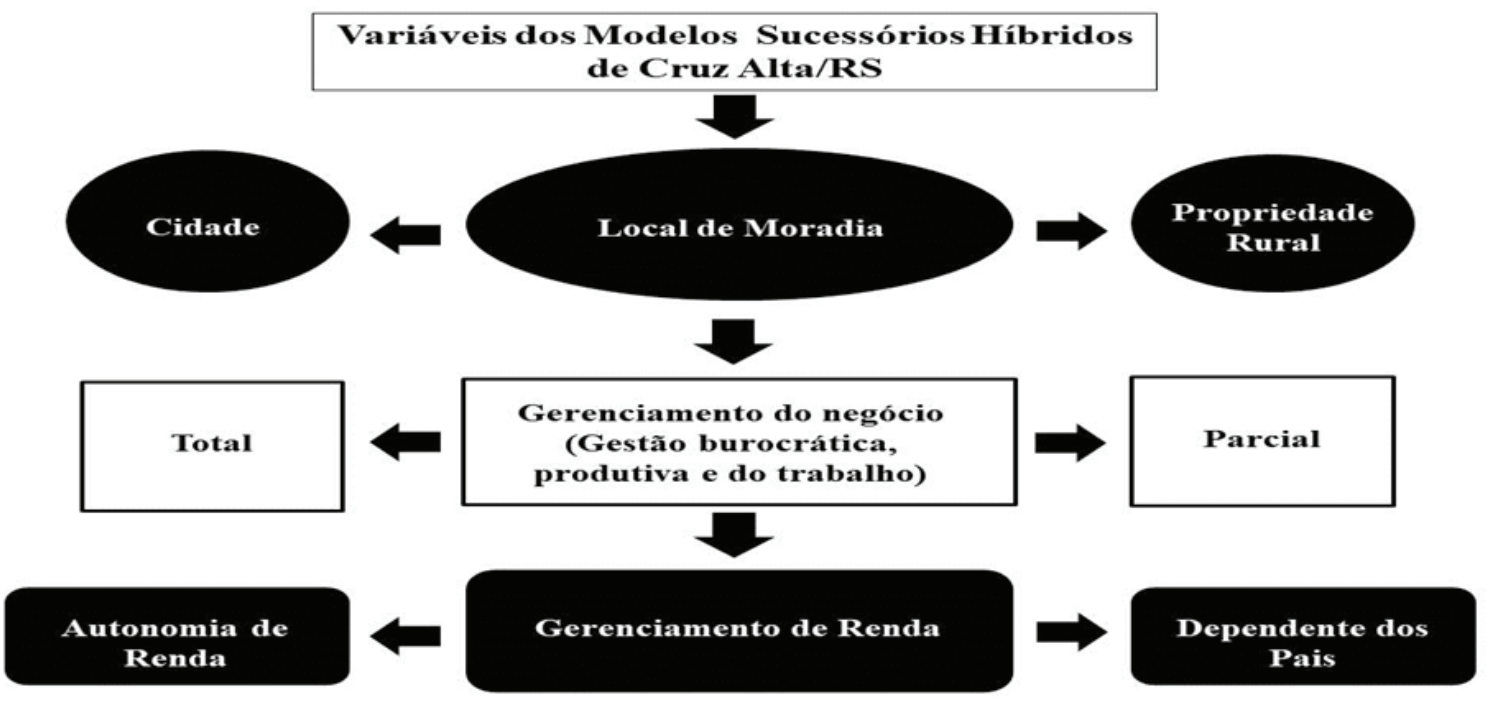

Fonte: Elaborada pelos autores a partir dos resultados da pesquisa (2018).

A seleção do local de moradia diz respeito ao fato de o sucessor residir na propriedade (meio rural) ou na cidade. Observou-se, nesta pesquisa, um número de sucessores que estão à frente dos negócios paternos que apresenta como local de moradia a cidade. Esta condição sugere outra perspectiva à tradicional forma de sucessão que ocorria nas propriedades nas gerações passadas que era viver no e do rural. Nestes casos, vive-se do rural, mas sem fazer do rural o local de moradia. A variável Administração dos Negócios leva em conta o que os sucessores fazem na questão da administração burocrática e produtiva da propriedade de forma geral.

A quase totalidade dos entrevistados afirma que os sucessores apresentam autonomia para a realização de alguns aspectos da gestão administração dos negócios, o que significa afirmar que a autonomia é dada ou estimulada pelos pais, mas de forma parcial. Em apenas cinco propriedades, os filhos têm autonomia total administrativa dos negócios. A variável Gerenciamento de Renda implica a forma como os pais distribuem a renda gerada pelos negócios da propriedade, considerando a forma como os sucessores são remunerados pelo trabalho executado. Foram identificadas três formas de gerenciamento da renda, sendo a primeira aquela em que os pais dividem ou remuneram os sucessores, a segunda trata do gerenciamento da renda ser de propriedade do sucessor e a terceira se refere ao fato de 
os sucessores não apresentarem gerenciamento e mostra uma condição de dependência do pai.

\section{Resultados e discussões}

Os resultados detalhados neste tópico buscam responder ao objetivo deste artigo que é discutir as formas como à sucessão geracional em propriedades rurais vem ocorrendo, buscando identificar a possibilidade da elaboração de novos arranjos referentes ao processo sucessório a partir da realidade encontrada. A elaboração destes tem como espelho os modelos sucessórios sugeridos por Gasson e Errignton (1993). É preciso ponderar as dificuldades em construir os modelos, devido à diversidade de situações em cada propriedade. Pode-se afirmar que os modelos são "híbridos", sendo difícil encontrar modelos puros conforme salientam Gasson e Errington (1993).

\section{Modelos sucessórios propostos a partir dos dados da pesquisa}

Os resultados advindos das entrevistas (considerando as variáveis selecionadas já apresentadas nos procedimentos metodológicos) permitem a construção dos seguintes modelos sucessórios, conforme exposto no Quadro 1.

Considerando as características internas de cada um dos modelos, são verificadas diferenças, conforme destacado a seguir.

Modelo 1 - Residência na propriedade, com autonomia na administração do negócio e com gerenciamento de renda.

Neste modelo, enquadram-se os entrevistados 2 e 24 . As propriedades são consideradas grandes (Entrevistado 2) e média (Entrevistado 24). Residem na propriedade e em casas separadas, ambos são casados, o Sucessor 2 é formado em Técnico Agrícola e o 24 tem ensino superior incompleto. No caso do Entrevistado 24, a família investiu na atividade leiteira como estratégia de fomento à sucessão. Os sucessores desenvolvem o trabalho agropecuário em tempo integral, aprendeu a atividade com o pai desde criança. 
Quadro 1 - Modelos sucessórios do município de Cruz Alta

\begin{tabular}{|c|c|}
\hline Modelos & Características \\
\hline $\begin{array}{c}\text { Modelo 1 } \\
\text { Entrevistados 2, 10,24, }\end{array}$ & $\begin{array}{c}\text { Residência na propriedade em casas separadas (um entrevistado } \\
\text { reside na cidade) } \begin{array}{c}\text { com autonomia na administração do negócio e } \\
\text { com gerenciamento de renda. }\end{array}\end{array}$ \\
\hline $\begin{array}{c}\text { Modelo 2 } \\
\text { Entrevistados }(9,15)\end{array}$ & $\begin{array}{c}\text { Residência na cidade, com autonomia na administração do negócio e } \\
\text { sem gerenciamento de renda. }\end{array}$ \\
\hline $\begin{array}{c}\text { Modelo 3 } \\
\text { Entrevistados }(1,6,8,11,12,21,25,27 \text { e 28) }\end{array}$ & $\begin{array}{c}\text { Residência na cidade, com gerenciamento parcial do negócio e com } \\
\text { gerenciamento de renda. }\end{array}$ \\
\hline $\begin{array}{c}\text { Modelo 4 } \\
\text { Entrevistados }(7,13,16,17,18,19,20,22)\end{array}$ & $\begin{array}{c}\text { Residência na propriedade, com administração parcial do negócio e } \\
\text { com gerenciamento de renda. }\end{array}$ \\
\hline $\begin{array}{c}\text { Modelo 5 } \\
\text { Entrevistados }(3,5,26,29,31)\end{array}$ & $\begin{array}{c}\text { Residência na cidade, com gerenciamento parcial do negócio, sem } \\
\text { gerenciamento da renda. }\end{array}$ \\
\hline $\begin{array}{c}\text { Modelo 6 } \\
\text { Entrevistados }(14,23 \text { e 30) }\end{array}$ & $\begin{array}{c}\text { Residência na propriedade, com administração parcial e sem } \\
\text { gerenciamento de renda. }\end{array}$ \\
\hline
\end{tabular}

Fonte: Elaborado pelos autores (2018).

A responsabilidade sobre o gerenciamento de negócios específicos dentro das propriedades é dos sucessores. Ou seja, os sucessores gerenciam atividades pontuais dentro da propriedade. No caso do Entrevistado 24, é a atividade leiteira. Considerando a situação do Entrevistado 2, este gerencia a produção de grãos de 100 hectares de uma área doada pelo pai. A renda da atividade que gerenciam é de total domínio dos sucessores.

No caso do Entrevistado 10, o que o diferencia é o fato de residir na cidade. O sucessor é do sexo masculino, casado, formado em Medicina Veterinária. Ressalta-se que, além da atividade agrícola, é Professor Universitário (o que representa outro ingresso de renda além da atividade agrícola da propriedade). O local de residência é na cidade, mas desenvolve o trabalho agropecuário na propriedade em tempo parcial, pois conta com mão de obra paga para auxiliar na atividade que aprendeu com o pai desde criança. Quanto às estratégias para motivar a sucessão, o Entrevistado 10 afirma ter investido em cavalos crioulos para incentivar a permanência do sucessor.

Neste caso, o sucessor está à frente dos negócios da propriedade, especialmente na produção de grãos. Ou seja, o Entrevistado 10 possui um negócio ou uma atividade independente (produção de grãos) dentro da propriedade que está sob sua responsabilidade.

Considerando a produção de grãos como um trabalho independente do sucessor, este tem autonomia administrativa de tocar todo o processo gerencial da atividade (incluindo gestão burocrática e produtiva). Quanto ao gerenciamento da renda, o sucessor também apresenta independência dos pais. O filho fica com dinheiro da atividade que gerencia e paga arrendamento para o pai. 
No geral, este modelo se assemelha com o segundo modelo de Gasson e Errington (1993), onde os filhos têm um negócio próprio na propriedade rural da família, porém em separado, residem nela e possuem boa autonomia na atividade que realizam, residem em casas separadas e têm autonomia sobre este negócio, dispõem de certa independência financeira, têm experiência nas atividades, pois desenvolveram desde criança. $\mathrm{O}$ filho desenvolveu e aprimorou as habilidades que aprendeu com o pai e possui relativa independência financeira, o que lhe permite construir algum capital próprio. No caso desta dissertação, ele tem autonomia na administração do negócio (produtiva, burocrática e trabalho) e com gerenciamento de renda.

Modelo 2 - Residência na cidade, com autonomia na administração do negócio e sem gerenciamento de renda.

São enquadradas neste modelo duas propriedades (Entrevistados 9 e 15), que são consideradas grandes. Os sucessores são do sexo masculino, sendo um solteiro e outro casado. Ambos são Engenheiros Agrônomos. Ressalta-se que, além da atividade agrícola, o sucessor pertencente ao Entrevistado 15 tem uma revenda de pneus (o que representa outro ingresso de renda além da atividade agrícola da propriedade).

Ambos residem na cidade. $\mathrm{O}$ sucessor do Entrevistado 9 se dedica à atividade em tempo integral e o Entrevistado 15 em tempo parcial, devido à outra atividade não agrícola. Os dois pagam mão de obra para auxiliar na execução do trabalho agrícola. Os sucessores aprenderam com o pai desde criança o exercício da atividade. Uma particularidade deste modelo é a presença das mães nos negócios agrícolas junto com os sucessores nas terras. As propriedades têm sua origem na herança materna. Os pais possuem empreendimentos não agrícolas no meio urbano. As mães entrevistadas afirmam ter partido delas o incentivo à sucessão levando os filhos a terem contato com a propriedade, apoiando o filho a cursar Agronomia.

Neste modelo, o sucessor está à frente dos negócios da propriedade, especialmente na produção de grãos no que se refere ao gerenciamento produtivo e burocrático. Quanto ao gerenciamento da renda, o sucessor também apresenta dependência da mãe, pois o controle financeiro das entradas de renda passa pelas mãos maternas. No entanto, as mães entrevistadas afirmam fornecer uma "ajuda de custo" aos sucessores.

Modelo 3 - Residência na cidade, com gerenciamento parcial do negócio e com gerenciamento de renda.

As características das terras que compõem este modelo são de propriedades grandes (em média 400 hectares) e apenas duas podem ser consideradas médias (com área em torno de 80 hectares). Todos os sucessores são do sexo masculino. A maioria é casada. Cinco sucessores 
(metade das propriedades enquadradas neste grupo) possuem formação em Engenharia Agronômica. A residência é urbana e sete dos sucessores desenvolvem somente o trabalho agrícola na propriedade em tempo integral, e a agricultura é uma atividade que aprenderam desde criança.

São propriedades onde os pais fizeram uso da estratégia de investir em outros negócios para cativar os sucessores (tais como investimentos em lavoura - família produzia gado de corte; área de terra, empresa de insumos agrícolas, unidade de recebimento de grãos e atividade leiteira). Nota-se que os investimentos para os sucessores estão voltados para o negócio agrícola; e, em dois casos, os investimentos não contemplam necessariamente a atividade realizada na propriedade, como é o caso dos investimentos na empresa de insumos agrícolas e unidade de recebimento de grãos.

Salienta-se que a administração dos negócios pelos sucessores é parcial. Isso se deve ao fato de que nenhum dos sucessores assume esta tarefa na sua totalidade. O que se observa é existir uma divisão de tarefas entre os pais e os sucessores. Por exemplo, as questões produtivas: plantar, fazer os tratos culturais, entre outras tarefas, estão sob a responsabilidade dos filhos (especialmente onde os sucessores são agrônomos), mas decisões sobre comercialização e investimentos são tomadas de comum acordo com os pais, ou decididas apenas pelos pais ou pelos filhos. Em outros casos, as decisões sobre comercializar a produção, investimentos e uso do dinheiro para a aplicação em uma atividade produtiva na propriedade, sob sua responsabilidade, são dadas aos filhos. O fato é que neste modelo, a administração dos negócios não tem os sucessores à frente de forma plena.

Quanto à participação no gerenciamento da renda, observa-se que os pais dividem os lucros com os sucessores ou até mesmo pagam salário. Nestes casos, os filhos recebem pelo trabalho executado, apresentando autonomia no uso e destino da renda gerada na propriedade, podendo destinar até mesmo para bens de consumo próprio.

Modelo 4 - Residência na propriedade, com administração parcial do negócio e com gerenciamento de renda.

Este modelo retrata que os sucessores pertencem a propriedades de distintos tamanhos: quatro configuram entre minifúndio e pequenas propriedades e quatro se enquadram como médias e grandes. A residência dos sucessores também apresenta particularidades: cinco residem na propriedade rural em casas separadas, sendo que apenas três na casa dos pais. Quanto ao sexo, três sucessores são mulheres. A escolaridade dos sucessores três é ensino fundamental; dois apresentam ensino médio, um está cursando Administração e dois já estão formados em Administração. Todos desenvolvem o trabalho agropecuário na propriedade em tempo integral. $\mathrm{E}$ as atividades agropecuárias aprenderam desde criança. 
Uma estratégia marcante desde grupo, para garantir a sucessão, é o investimento na atividade leiteira como geração de renda, sendo esta estratégia utilizada por sete entrevistados dos oito que compõem este grupo.

Os sucessores apresentam uma visão administrativa parcial dos negócios, dividindo as atividades com os pais, ou seja, sem uma autonomia de todo o processo. No entanto, quando se trata do gerenciamento da renda, verifica-se situação distinta. Em quatro propriedades, os pais dividem os lucros com os sucessores; em duas, os sucessores recebem salários; em outras duas, os filhos têm autonomia de renda da atividade que gerenciam. Aqui se encontra a situação do Entrevistado 17, onde é a filha sucessora que gerencia o negócio e fica com a renda. Situação semelhante é o do Entrevistado 22 que também apresenta a filha sucessora (a qual vivenciou uma experiência de trabalho urbano e retornou), dividindo a gestão dos negócios e a renda com o irmão. Outra situação é apresentada pelo Entrevistado 13, na qual a filha compartilha a sucessão com o irmão, dividindo os lucros da propriedade com ele e o pai.

O modelo 3 e 4 encontrado neste trabalho em parte se parece bastante com o modelo 3 de Gasson e Errington (1993): os filhos residem na propriedade, na casa dos pais (modelo 4), desenvolvem somente trabalho agropecuário em tempo integral, aprenderam a atividade com o pai desde criança, trabalham em parceria (modelo 3 e 4). O filho vai gradualmente aumentando sua responsabilidade na realização de algumas atividades, com possibilidade de tomada de decisão em determinadas tarefas em comum acordo com o pai. Assim como neste, o filho desenvolve a gestão do trabalho parcial, gestão burocrática e produtiva parcial, porém a gestão financeira é plena do pai. A tendência é o filho ir gradualmente aumentando sua responsabilidade na realização das atividades, com possibilidade da tomada de decisão em comum acordo com o pai.

Modelo 5 - Residência na cidade, com gerenciamento parcial do negócio, sem gerenciamento da renda.

Neste modelo, são cinco grandes propriedades. Quanto ao estado civil, quatro sucessores são casados, sendo três formados em Engenharia Agronômica e dois cursando esta graduação. Três sucessores são do sexo masculino e dois femininos. Todos residem na cidade. Os estudantes dedicam tempo parcial e o restante dos sucessores destina todo o tempo para a atividade agrícola. O Entrevistado 5 afirma ter investido em terras como fomento a permanência do sucessor.

A autonomia da gestão administrativa é parcial, ficando a cargo dos sucessores a realização de algumas atividades pontuais, especialmente na parte produtiva em razão da qualificação profissional. No entanto, quando se analisa o gerenciamento da renda, verifica-se que os pais afirmam 
dividir os lucros com os filhos. Porém, os pais detêm o controle da conta, liberando o dinheiro de acordo com a necessidade do sucessor. Importante ressaltar que esta característica inclui não apenas os filhos sucessores que ainda estudam, mas inclusive os sucessores já casados e com residências separadas. Conclui-se que a autonomia é relativa, dentro destes casos, pois a independência acontece nos espaços da moradia, nos demais espaços (inclusive da renda) o pai busca permanecer com o controle.

Modelo 6 - Residência na propriedade, com administração parcial e sem gerenciamento de renda.

Neste modelo, encontram-se duas propriedades consideradas pequenas e uma grande. Todos residem na propriedade, na casa paterna e são solteiros. Quanto ao sexo, duas propriedades têm as filhas como sucessoras e na outra é o filho. A escolaridade do filho sucessor é Curso Técnico Agrícola incompleto, uma sucessora é Médica Veterinária e a outra faz Ensino Médio. O tempo dedicado à atividade agrícola é parcial (para os sucessores que estudam) e integral para o outro caso. Sobre os investimentos, os Entrevistados 14 e 23 investiram em leite e o Entrevistado 30 em bovinos de corte $\mathrm{PO}$ da raça Angus visando à permanência dos filhos na propriedade.

A autonomia dos negócios é parcial, pois os filhos ficam responsáveis por determinadas tarefas, sem apresentar autonomia absoluta em qualquer uma das atividades burocráticas ou produtivas. Considerando a autonomia monetária, os sucessores recebem "ajuda financeira" ou mesada dos pais, podendo variar conforme a capacidade da propriedade e da família. No entanto, o controle da conta fica a cargo do principal gestor.

O modelo 5 e 6 se assemelha em partes com o modelo 4 de Gasson e Errington (1993). O filho mora com o pai, mas participa muito pouco do processo da tomada de decisões das atividades na propriedade rural, apesar de conviver e trabalhar com seu pai e sua família por muitos anos no mesmo estabelecimento. $\mathrm{O}$ filho é tido como uma força de trabalho importante na propriedade rural e assume como sucessor em caso da morte ou aposentadoria do pai. Porém, neste caso, os filhos estão se preparando para a atividade, todos fizeram ou estão fazendo curso de Agronomia, ou seja, terão preparo para assumir a gestão produtiva, mas estarão menos preparados para assumir a propriedade rural em razão da pouca experiência administrativa realizada durante sua vida conforme salienta Abramovay et al. (1998).

Outra questão que perpassa todos os modelos é uma característica já apontada por estudos sobre sucessão geracional no sul do Brasil: a "sucessão tardia”. Segundo Abramovay et al. (1998), Stropasolas (2006) e Spanevello (2008), este modelo tem como principal característica o encaminhamento e 
2 Segundo Curia, Céspedes, Nicoletti (2015) os processos referentes à herança são definidos legalmente pelo Código Civil brasileiro, pela Lei ${ }^{\circ} 10.406$, de 10 de janeiro de 2002, tem direito a herança todos os filhos legítimos e testamentários. a divisão do patrimônio "transmissão dos bens patrimoniais" ao final da vida dos pais, ou quando estes estão incapazes física ou mentalmente de gerir a propriedade. Os autores destacam que tende a ser um processo prolongado. Percebe-se que mesmo os primeiros estudos constatarem isso há 20 anos, o mesmo é percebido neste trabalho, onde os pais de uma forma ou outra estão no controle da propriedade e a maioria não decidiu o momento da sucessão. Os pais alegam que ocorrerá somente depois da aposentadoria, uns dizem ser no final da vida e, por fim, outros afirmam que apenas transferirão quando não tiverem mais condições de saúde. Neste estudo, apenas três produtores já transferiram ao sucessor. Os resultados corroboram com os autores, percebe-se a sucessão em processo de encaminhamento, ou seja, longe de que ocorra plena na maioria dessas propriedades. Os sucessores apresentam grande parte da autonomia produtiva sobre o negócio da família; porém, poucos apresentam o gerenciamento sobre as finanças e renda da propriedade. Os pais estão muito presentes neste controle.

A herança não foi discutida em boa parte das propriedades, em outras será conforme a lei ${ }^{2}$ ou testamento, e em algumas a divisão será igualitária. Ou seja, o encaminhamento da herança e da sucessão está muito ligado ao apego do pai a terra e à propriedade. A sucessão e herança neste trabalho têm sido vista na forma "encaminhada" no sentido de os patriarcas mobilizarem os sucessores a permanecerem na propriedade na forma de mão de obra ou "pseudo" gestores de produção, ou no sentido de provocar o sucessor a trabalhar em algo que será deles no futuro próximo. Ocorre na maioria das propriedades a falta de planejamento sucessório, ou seja, somente ocorrerá com a falta de condições dos pais tanto física como mental na maioria dos modelos.

Ainda, como resultado dos modelos, as propriedades com sucessoras não representam a maioria, já que a prioridade é pelo filho homem. O que corrobora com o estudo de Gasson e Errington (1993), no qual concluem que a sucessão da propriedade rural é feita através da linha masculina. Em seguida, a característica do negócio agrícola e particularmente a sua dimensão (tamanho) são condicionantes à sucessão. Neste estudo, percebese que a sucessão feminina tem ocorrido em propriedades caracterizadas como minifúndios e pequenas propriedades, onde a principal atividade produtiva é a pecuária leiteira, fomentadora da sucessão feminina. O investimento nesta atividade tem sido a principal estratégia mobilizadora da sucessão neste tipo de propriedade.

Nos resultados de Gasson e Errington (1993), os tamanhos das propriedades influenciam diretamente na identificação de um sucessor. $\mathrm{O}$ principal viés nas últimas pesquisas demonstra que as propriedades maiores são mais propensas a identificar um sucessor. $\mathrm{O}$ tamanho da propriedade é relatado tanto para Gasson et al. (1988) como para Errington e Trander 
(1991 apud GASSON, ERRINGTON, 1993), os quais descobriram, na amostra de sua pesquisa, que em $35 \%$ das propriedades de 50 hectares ou menos se identifica um sucessor, enquanto em propriedades de 500 hectares ou mais, em $62 \%$, identificaram um sucessor. No entanto, estes resultados são vistos neste estudo, onde propriedades maiores têm mais condições de formar ou ter um sucessor disposto a assumir com a falta do pai. Os sucessores são preparados para o "cargo" nas propriedades de melhores condições, são formados em cursos que lhes darão a autonomia produtiva da propriedade e a gestão plena apenas com a retirada do pai.

$\mathrm{O}$ interesse em ter um sucessor expõe o desejo a respeito da busca individual pela imortalidade. O negócio fica tão ligado à identidade pessoal, que sua manutenção em gerações futuras preserva essa identidade. Fornece um meio para a presente geração influenciar o futuro das outras. $\mathrm{O}$ sentido de identidade está associado não tanto com o negócio da família, mas com a terra que ela ocupa (GASSON; ERRINGTON; 1993).

Nestes modelos sucessórios aqui caracterizados, são poucos os que possuem sucessores os quais apresentam gestão plena ou autonomia sobre os negócios da família ou da propriedade rural. Os pais detêm o controle sobre a renda e grande participação sobre a gestão administrativa da propriedade. Ademais, os pais também condicionam a qualificação profissional dos sucessores, com estudos técnicos e superiores voltados à linha das agrárias; porém, os pais detêm o controle financeiro dos lucros da propriedade ou da atividade, e o apego à propriedade e a terra é grande. Os sucessores, em suma, são grandes gestores produtivos. Neste caso, entram as técnicas produtivas, como tratos culturais, variedades, época de plantio, adubação, ficando no encargo da busca de inovações e tecnologias voltadas à agropecuária, visando à produção e produtividade da propriedade. Logo o controle financeiro, a distribuição dos lucros é responsabilidade dos pais, os quais impõe condições ou são os grandes responsáveis pela gerência destes valores.

\section{Considerações finais}

A partir dos resultados encontrados, foi possível a elaboração de seis modelos. $\mathrm{Na}$ maioria dos modelos, os sucessores não têm a gestão plena sobre o negócio, tanto administrativa como sobre a renda da família, e é grande a presença do patriarca, principalmente sobre a gestão financeira da propriedade. Os sucessores têm grande participação na gestão produtiva da propriedade, pois os pais financiam ou mobilizam esta qualificação através de cursos técnicos e superiores, pensando no futuro da propriedade.

As relações de gênero nestes modelos e nas estratégias ou a escolha que justifica a preferência pelos filhos à sucessão têm sido totalmente 
voltadas ao filho (homem); às filhas, na maioria dos casos, cabem o estudo e a qualificação em outras áreas e a vida urbana. Os pais são muito apegados à tradição familiar, a terra, à propriedade, quase sempre destinando ao filho homem a continuidade da propriedade. Ademais, a chance de as filhas serem sucessoras se resume praticamente aos casos onde elas são mão de obra na propriedade, trabalhando especialmente na atividade leiteira e, em sua maioria, vistas em propriedades caracterizadas como pequenas ou minifúndios onde a atividade é tida como estratégia mobilizadora e fomentadora da sucessão. As filhas passam a ter direito igualitário a terra quando o patrimônio entra em processo de herança (divisão da terra) nas propriedades, ou em caso de morte ou falta de condições de saúde do patriarca, por meio da divisão sobre a área pela forma da lei.

Uma das principais conclusões deste trabalho são as adaptações do modelo de sucessão tardia. Os pais “cedem" bens materiais, autonomia para os filhos na forma de estratégias, mas não cede a gestão efetiva e nem o patrimônio e nem têm nas filhas a preferência pela sucessão. No total das propriedades analisadas, à frente dos negócios estão apenas cinco sucessores. Ainda, ressalta-se nesta pesquisa a figura mais evidente do sucessor - gestor do que propriamente o sucessor como mão de obra. Particularmente, em propriedades maiores, a presença do sucessor como gestor do negócio ficou mais evidente, desobrigando-o a atuar como mão de obra devido às possibilidades financeiras das propriedades permitirem a contratação de funcionários. Outra constatação é que um percentual de gestores não reside no meio rural, o que significa dizer que é cada vez mais evidente pensar que a sucessão geracional está atrelada, de forma conceitual, à sucessão do negócio e não a ter de viver na propriedade e no meio rural. Ou seja, é necessário compreender estas mudanças em torno da sucessão geracional, que tenta se manter revestida de uma série de adaptações tais como a maior presença do sucessor gestor que reside no meio urbano.

No entanto, é preciso ponderar que as discussões dos modelos sucessórios aqui apresentados precisam ser relativizadas, pois a temática da sucessão geracional é complexa e os dados apresentados tratam de um universo localizado, necessitando de outras pesquisas para aprofundar os resultados encontrados. Mesmo assim, este estudo é entendido como relevante para pensarmos ações e políticas públicas para a reprodução socioeconômica do agronegócio e do desenvolvimento rural como um todo.

\section{Referências}

ABRAMOVAY, R. et al. Juventude e agricultura familiar: desafios dos novos padrões sucessórios. Brasília: Edições Unesco, 1998.

ALMEIDA, M. W. B. Redescobrindo a família rural. Revista Brasileira de Ciências Sociais. São Paulo, v.1, n.1, p. 66-83, jun.1986. 
BARDIN, L. Análise de conteúdo. Lisboa: edições, 1997. v. 70.

BOURDIEU, P. Reprodução Proibida: a dimensão simbólica da dominação econômica. In:: BOURDIEU, P. O campo econômico: a dimensão simbólica da dominação. Tradução Roberto Leal Ferreira. Campinas: Papirus, 2000. p. 93-119.

CAMPOS, C. J. G. et al. Método de análise de conteúdo: ferramenta para a análise de dados qualitativos no campo da saúde. Revista Brasileira de Enfermagem, 2004. Disponível em: http://www.scielo.br/pdf/reben/v57n5/a19v57n5. Acesso em: 21 maio 2018.

CAMPOS, C. S. S; MEDEIROS, R. M. V. Pobreza feminina: um subproduto pouco visível da riqueza do agronegócio: caso de Cruz Alta/RS. Ensaios FEE, v. 33, n. 1, 2012.

CHAMPAGNE, P. La reproduction. Actes de la Recherche en Sciences Sociales, Paris, n. 65, p. 41-64, nov. 1986.

CURIA, L. R.; CÉSPEDES, L.; NICOLETTI,J. Vade Mecum OAB e concursos. 5. ed. atual. ampl. São Paulo: Saraiva, 2015.

ELLIS, F. Rural livelihoods and diversity in developing countries. Oxford: Oxford University Press, 2000.

ERRINGTON,A.Handing over the reins:A comparative study of intergenerational farm transfers in England, France and Canada. Zaragoza, Spain, v. 28, p. 31, 2002.

GASSON, R. et al. The farm as a family business: a review. Journal of Agricultural Economics, v. 39, n. 1, p. 1-41, 1988.

GASSON, R.; ERRINGTON, A. The farm family business. Wallingford: Cab International, 1993.

INSTITUTO NACIONAL DE COLONIZAÇÃO E REFORMA AGRARIA (INCRA). Tamanhos das propriedades rurais. Disponível em: http://www.incra. gov.br/tamanho-propriedades-rurais. Acesso em: 21maio 2017.

INSTITUTO BRASILEIRO DE GEOGRAFIA E ESTATÍSTICA (IBGE). Histórico de Cruz Alta-RS. 2018. Disponível em: http://biblioteca.ibge.gov.br/ visualizacao/dtbs/riograndedosul/cruzalta.pdf. Acesso em: 21 maio 2018.

MATTE, A. Vulnerabilidade, capacitações e meios de vida dos pecuaristas de corte da Campanha Meridional e Serra do Sudeste do Rio Grande do Sul. 2013. 176 f. Dissertação (Mestrado em Desenvolvimento Rural) - Programa de PósGraduação em Desenvolvimento Rural, Universidade Federal do Rio Grande do Sul, Porto Alegre, 2013.

PAULILO, M. I. Trabalho familiar: uma categoria esquecida de análise. Revista Estudos Feministas, Florianópolis, v. 12, n. 1, p. 229-252, jan./abr. 2004.

SILVESTRO, $\mathrm{M}$, et al. Os impasses sociais da sucessão hereditária na agricultura familiar. Brasília: Florianópolis: EPAGRI-NEAD, 2001.

SPANEVELLO, R. M. A dinâmica sucessória na agricultura familiar. 2008. 236 f. Tese (Doutorado em Desenvolvimento Rural) - Programa de Pós-Graduação em Desenvolvimento Rural, Universidade Federal do Rio Grande do Sul, Porto Alegre, 2008. 
SPANEVELLO, R,. M. et al. Migração juvenil e implicações sucessórias na agricultura familiar. Revista de Ciências Humanas, v. 45, p. 291-304, 2011.

SPANEVELLO, R,. M. et al. As estratégias para manter a sucessão em estabelecimentos familiares. In: RENK, A.; DORIGON, C. (Org.). Juventude rural, cultura e mudança social. Chapecó: Argos, 2014. p. 163-188.

SPANEVELLO, R. M. et al. A Problemática do Envelhecimento no Meio Rural sob a Ótica dos Agricultores Familiares sem Sucessores. Desenvolvimento em Questão, v. 15, n. 40, p. 348-372, 2017.

STROPASOLAS, V.L. O Mundo Rural no Horizonte dos Jovens. Florianópolis: Editora da UFSC, 2006.

WOORTMANN, E. Herdeiros, parentes e compadres: colonos do Sul e sitiantes no Nordeste. São Paulo: Hucitec; Brasília: Editora da UNB, 1995.

Submetido em: 03/10/2018.

Aceito em: 28/04/2019. 


\title{
SUCCESSION MODELS ON RURAL PROPERTIES: A STUDY IN THE MUNICIPALITY OF CRUZ ALTA / RS
}

\begin{abstract}
The generational succession in rural properties, especially in southern Brazil, is characterized by a late succession model because parents wait the age limit to pass the business management and the heritage to the children. However, the possibilities of rural youth migration impose new perspectives on succession, and can generate different models. The aim of this article is to discuss the ways in which the generational succession in rural properties has been attempting to identify the possibility of elaborating new arrangements regarding the succession process. The empirical town of the data collection was Cruz Alta/RS, through 31 interviews with rural producers which had generational succession in the properties. For the analysis and elaboration of the models, three variables were considered: place of residence; business administration and income management. The results point to a diversity of succession models. In total, six models were elaborated, showing that the generational succession has been taking place in different forms, including the possibility of the successors live in the urban area, with more or less autonomy in the businesses and the income management. These results suggest that the process of generational succession in rural properties has been happening in those the parents motivate the permanence of the children, ensuring them autonomy in the management of productive activities, housing and income as a way to stimulate their permanence.
\end{abstract}

Keywords: Generational succession. Models. Rural properties

\section{MODELOS SUCESORIOS EN PROPIEDADES RURALES: UN ESTUDIO EN EL MUNICIPIO DE CRUZ ALTA/RS}

\begin{abstract}
Resumen
La sucesión generacional en propiedades rurales, especialmente en el Sur de Brasil, se caracteriza por un modelo sucesorio tardío en el que los padres esperan hasta el límite de edad para pasarles la gestión de los negocios y el patrimonio a sus hijos. Las posibilidades de la migración juvenil rural, sin embargo, han impuesto nuevas perspectivas cuanto a la sucesión y pueden generar modelos diferentes. El objetivo de este artículo es discutir las formas como se ha llevado a cabo la sucesión generacional en propiedades rurales, e identificar la posibilidad de que se elaboren nuevos mecanismos referentes al proceso sucesorio. El espacio empírico de la recolección de datos fue el municipio de Cruz Alta/RS, en el que se realizaron 31 entrevistas con productores rurales con sucesión generacional en las propiedades. Para el análisis y la elaboración de los modelos se consideraron tres variables: local de residencia; administración del negocio y gestión de ingresos. Los resultados indican una diversidad de modelos sucesorios. En total, se elaboraron seis modelos que demuestran que la sucesión generacional se ha ido realizando de distintas formas, incluyendo la posibilidad de que los sucesores residan en el medio urbano, con más o menos autonomía en la gestión de los negocios y de la renta. Estos resultados sugieren que el proceso de sucesión generacional en propiedades rurales viene ocurriendo en propiedades en las que los padres motivan a sus hijos para que permanezcan en el lugar, y fomentan su permanencia asegurándoles autonomía en la gestión de actividades productivas, residencia y renta.
\end{abstract}

Palabras clave: Sucesión generacional. Modelos. Propiedades rurales. 